Psychological Medicine, 1990, 20, 471-473

Printed in Great Britain

EDITORIAL

\title{
Disease, illness, sickness; impairment, disability and handicap ${ }^{1}$
}

In 1980, the World Health Organization (WHO) adopted a triad of definitions for impairment, disability and handicap to describe stable and persisting disorders in an International Classification (WHO, 1980). Evidently, for those who work with patients with chronic disorders, they provide a useful conceptual framework. The concepts have come to be used especially in the field of rehabilitation, including psychiatric disorders.

Historically, these concepts were preceded by another triad of concepts which gave separate identity to disease, illness and sickness. This dual framework around disease and around impairment enlarges the focus of the classification of disorders. An exclusive concern with medical diagnosis, aetiology and prognosis is broadened to include concerns with the psychological and social dimensions of disorder. In what follows, I outline sources of these concepts, and define the terms as I proceed. The perspective I adopt is not that of a scholar and historian but of a participant. Thus, the antecedents I emphasize are those that impinged most on my own unfolding perceptions.

Sickness as a social idea has a long history. It is only recently, however, that we have begun to attain clarity about the array of concepts that have been applied to sickness, both physical and mental. Two major scholars, the Swiss medical historian Henry Sigerist and the American sociologist Talcott Parsons, opened the modern address to the theoretical issues.

Sigerist traced the evolution of the special position accorded sick persons by different societies through history. This special position, he held, was distinct from the disease itself and entailed a social role with privileges and obligations. Parsons developed this idea in terms of what he named the sick role. A role describes the obligations and expectations that attach to a given social status, and the sick role describes the social expectations that attach to the status of sickness. The essence of the notion of the sick role is to discriminate the underlying disease process in the individual from the social position accorded to a sick person by his or her society.

My own first enlightenment, while grappling with the applications of sociology to medicine in England in the late 1950s, was no more than a flash from a seminal footnote on the sick role in The Social System, Parson's monumental work of 1951 (Parsons, 1951). Soon after, I came upon a predecessor of Parsons' footnote in Sigerist's insightful essay published in 1929 (Sigerist, 1929). Somewhat later, I found further illumination on the sick role in a paper by Parsons \& Fox (1952). The idea was carried forward a little by William Watson and me (Susser \& Watson, 1962); we differentiated among the forms the sick role might take in societies that differed in levels of economic development, culture and disease patterns. In particular, we separated chronic and ambulant forms of the sick role from the prototypical acute bedridden form (see also Twaddle \& Hessler, 1977).

From these early reflections, the elements of the triad - disease, illness and sickness - gradually emerged, and they were defined by Watson and me in a second edition of our book in 1971 (Susser \& Watson, 1971). Disease was the term reserved for objective physiological or mental disorder at the organic level and confined to the individual organism. Illness was reserved for a subjective state, a psychological awareness of dysfunction at the personal level also confined to the individual. Sickness was used, in the manner of Sigerist and Parsons, to refer to a state of social dysfunction, a social role assumed by the individual that is variously specified according to the expectations of a given society, and that thereby extends beyond the individual to include relations with others.

The notion of handicap underwent a parallel evolution. The descriptive triad that emerged is exactly analogous with that around disease. In the United States, studies of the social acceptance

' Address for correspondence: Professor Mervyn Susser, Gertrude H. Sergievsky Center, Columbia University, 630 W. 168th St, New York, NY 10032, USA. 
of injury and handicap by Barker and his colleagues (Barker et al. 1948; Ladieu et al. 1948) were under way in the late 1940s, and variously tested by Richardson et al. (1961). These studies addressed the attitudes and psychological responses of other individuals to handicapped persons. A clear distinction between these social and psychological interactions of the handicapped person with others, on the one hand, and the underlying physical disability on the other, was made by Wright (1960) in her book Physical Disability.

Alongside the evolving ideas among social psychologists in the early 1950 s, a sociological line of thought flowed from the theory of social deviance of Lemert (1951). In interpreting 'social pathology' of all forms, Lemert postulated two stages of deviance. Primary deviance is the initial act of the individual, which can be the result of a wide variety of social, psychological and physical forces. Secondary deviance is deviant behaviour that follows on societal reaction to the primary act and that, if continued, takes on the character of a persisting social role.

The general paradigm underlying this theory applies no less well to mental disorder that is presumed to be stable and persisting than it does to stable and persisting physical disability. Early in this century, the leading Swiss psychiatrist Eugen Bleuler (1911) had recognized that symptoms primary to mental disorder should be differentiated from other symptoms secondary to institutional life. Significant developments of similar ideas in the social sciences were made, a half-century later in the United States, by Irwin Goffman (1961) and by Thomas Scheff (1966). Goffman characterized different roles assumed by psychiatric patients in institutions. In his labelling theory, Scheff gave fresh and perhaps undue emphasis to these secondary aspects of chronic mental disorder in his claim that societal reaction is 'perhaps the single most important cause' of such conditions (Scheff, 1966 pp. 92-93).

A number of workers in the practical fields of chronic disability and of chronic mental disorder strove independently to refine related concepts for application. In the United States, Hamilton (1950) in defining 'disability' as '... a condition of impairment...' separated it from 'handicap', defined as deficient function indicated by the obstacles interposed by the disability. Saad Nagi (1965), Lawrence Haber (1967) and Richard Burk (1967) separated the pathology underlying disabilities from individual performance and social roles.

While, in general, the American work was theoretical, British work was empirical. In Britain, the Medical Research Council Social Psychiatry Research Unit, directed by Sir Aubrey Lewis, was a focus for similar lines of thinking and research in both psychiatric disorders and mental retardation. In the 1950s and 1960s, studies of psychiatric disorders in social context by Maurice Carstairs, John Wing, George Brown, and others (see Wing, 1967), and studies of mental retardation by Neil O'Connor \& Jack Tizard (1956), laid the foundation for theoretical advances in empirical research.

Following upon a parallel effort to bring these various ideas and researches together in a coherent framework in the mid 1960s, we defined the triad for stable, persisting disorders of impairment, disability and handicap in strict symmetry with the triad for dynamic disorders of disease, illness, and sickness (Susser, 1965, 1968; Stein \& Susser, 1971; Susser et al. 1985). The division between what is dynamic and what stable will usually be evident, although it can result in occasional ambiguities. Sometimes what is persisting and appears stable, for example chronic schizophrenia, belies the appearance of stability with a fluctuating course and more properly belongs in the disease triad.

Impairment, analogous with disease, refers to a stable and persisting defect in the individual at the organic level which stems from known or unknown molecular, cellular, physiological or structural disorder. Disability, analogous with illness, refers to stable and persisting physical or psychological dysfunction at the personal level, by necessity again confined to the individual; this dysfunction stems from the limitations imposed by the impairment and by the individual's psychological reaction to it. Handicap, like sickness, refers to persisting social dysfunction, a social role assumed by the impaired or disabled individual that is assigned by the expectations of society. Handicap stems, that is, not from the individual but from social expectations; it follows from the manner and degree in which expectations alter the performance of social roles by impaired or disabled persons. I should note that these definitions are slightly modified in the WHO International Classification, especially with regard to handicap. 
As defined here, the terms within each triad - both those that describe disorders in process and those that describe stable conditions - cannot be used as synonyms for each other; they do not necessarily have one-to-one relationships one with the other. A person may have an organic disorder without feeling ill; the sense of being ill entails neither organic disorder nor the automatic assumption of a social role appropriate to sickness and the seeking or receiving of care; and a person who malingers can perform the sick role without being ill or impaired. Likewise, a person who has a congenital or acquired impairment may not be functionally disabled or socially handicapped; functional disability (as with mild mental retardation) may not be grounded in any organic impairment; and persons assigned a handicapped role (as in the past with many admitted to institutions for the mentally retarded, epileptic colonies and the like) might not be functionally disabled or even organically impaired.

The epidemiological, clinical and care-giving applications of these concepts are many. For insight into them, the reader must go beyond this capsule history to other sources (Twaddle \& Hessler, 1977; Susser et al. 1985). The social science literature provides theoretical background. In the psychiatric literature, the applications are best developed (under somewhat different terminology) by British writers whose ideas have grown from a steady address to the problems of social psychiatry in a research programme continuing over the past thirty years (Wing \& Morris, 1981). In the field of disability and handicap, too, the most extensive application is to be found in a British publication (Patrick \& Peach, 1989).

MERVYN SUSSER

Bruce Link, Donald Patrick, Stephen Richardson and Ezra Susser all made comments which contributed to this editorial in its finished form. Ezra Susser and Jerome Vaccaro induced me to write it.

\section{REFERENCES}

Barker, R. G., Adler, D. \& Dembo, T. (1948). The social psychology of physical disability. Social aceptance of the injured. Journal of Social Issues 4, 28 . 34.

Bleuler, E. (1911). Dementia Praecox or the Groups of Schizophrenias. (Transl. J. Zinkin.) National Universities Press: New York, 1950.

Burk, R. D. (1967). The nature of disability. Journal of Rehabilitation $33,1014$.

Goffman, E. (1961). The moral career of the mental patient. In Asy'ums (ed. E. Goffman), pp. 125-169. Anchor Book, Doubleday: New York.

Haber, L. (1967). Idenifying the Disabled: Concepts and Methods in the Measurement of Disability. Social Security Bulletin, US Department of Health, Education and Welfare. Social Security Administration.

Hamilton, K. (1950). Counselling the Handicapped. Ronald Press: New York.

Ladieu, G., Adler, D. \& Dembo, T. (1948). Studies in adjustment to visible injuries: social acceptance in the injured. Journal of Social Issues 4, 5561 .

Lemert, E. M. (1951). Social Pathology. McGraw Hill: New York.

Nagi, S. (1965). Some conceptual issues in disability and rehabilitation. In Sociology and Rehabilitation (ed. M. B. Sussman), pp. 100 113. American Sociological Association: Washington, DC.

O'Connor, N. \& Tizard, J. (1956). The Social Problem of Mental Deficiency. Pergamon: London.

Parsons, T. (1951). The Social System. The Free Press: Glencoe, Illinois.

Parsons, T. \& Fox, R. (1952). Illness, therapy and the modern urban American family. Journal of Social Issues 8, 31-44.

Patrick, D. \& Peach, H. (1989). Disablement in the Community. Oxford University Press: Oxford.

Richardson, S. A., Hasdorf, A. H., Goodman, N. \& Dornbusch, S.
M. (1961). Cultural uniformity in reaction to physical disabilities. American Sociological Review 20, 241-247.

Scheff, T. (1966/1984). Being Mentally III: a Sociological Theory, 2nd edn. Aldine: Chicago.

Sigerist, H. (1929). The special position of the sick (transl. R. Connell). In Sigerist on the Sociology of Medicine (ed. M. I. Roemer and E. Henry), pp. 9-22. MD Publications: New York. York.

Stein, Z. \& Susser, M. (1971). Changes over time in the incidence and prevalence of mental retardation. In Exceptional Infant 2: Studies in Abnormality (ed. J. Helmuth), pp. 305-340. Brunner/Mazel: New York.

Susser, M. (1965). Rationale for community care of psychiatric disorder. Medical Care 3, 52-59.

Susser, M. (1968). Community Psychiatry: Epidemiological and Social Themes. Random House: New York.

Susser, M. W. \& Watson, W. B. (1962). Sociology in Medicine, Ist edn. Oxford University Press: London.

Susser, M. W. \& Watson, W. B. (1971). Sociology in Medicine, 2nd edn, pp. 16-17, 29, 216-218, 295 fr., 473. Oxford University Press: London.

Susser, M., Watson, W. \& Hopper, K. (1985). Sociology in Medicine, 3rd edn. Oxford University Press: New York.

Twaddle, A. C. \& Hessler, R. M. (1977). A Sociology of Health. Mosby: St Louis.

Wing, J. K. (1967). The modern management of schizophrenia. In New Aspects of the Mental Health Services (ed. H. Freeman and J. Farndale), pp. 3-28. Pergamon: Oxford.

Wing, J. K. \& Morris, B. (1981). Clinical basis of rehabilitation. In Handbook of Psychiatric Rehabilitation Practice (ed. J. K. Wing and B. Morris), pp. 3-26. Oxford University Press: Oxford.

World Health Organization (1980). International Classification of Impairments, Disabilities and Handicaps. WHO: Geneva.

Wright, B. A. (1960). Physical disability: a Psychological Approach. Harper: New York. 